\title{
Health Information Technology Continues to Show Positive Effect on Medical Outcomes: Systematic Review
}

Clemens Scott Kruse, MBA, MHA, MSIT, PhD; Amanda Beane, BA

School of Health Administration, Texas State University, San Marcos, TX, United States

Corresponding Author:

Clemens Scott Kruse, MBA, MHA, MSIT, PhD

School of Health Administration

Texas State University

601 University Drive

Encino Hall, Rm 250

San Marcos, TX, 78666

United States

Phone: 15122454462

Fax: 15122458712

Email: scottkruse@txstate.edu

\begin{abstract}
Background: Health information technology (HIT) has been introduced into the health care industry since the 1960s when mainframes assisted with financial transactions, but questions remained about HIT's contribution to medical outcomes. Several systematic reviews since the 1990s have focused on this relationship. This review updates the literature.

Objective: The purpose of this review was to analyze the current literature for the impact of HIT on medical outcomes. We hypothesized that there is a positive association between the adoption of HIT and medical outcomes.

Methods: We queried the Cumulative Index of Nursing and Allied Health Literature (CINAHL) and Medical Literature Analysis and Retrieval System Online (MEDLINE) by PubMed databases for peer-reviewed publications in the last 5 years that defined an HIT intervention and an effect on medical outcomes in terms of efficiency or effectiveness. We structured the review from the Primary Reporting Items for Systematic Reviews and Meta-Analysis (PRISMA), and we conducted the review in accordance with the Assessment for Multiple Systematic Reviews (AMSTAR).

Results: We narrowed our search from 3636 papers to 37 for final analysis. At least one improved medical outcome as a result of HIT adoption was identified in $81 \%$ (25/37) of research studies that met inclusion criteria, thus strongly supporting our hypothesis. No statistical difference in outcomes was identified as a result of HIT in $19 \%$ of included studies. Twelve categories of HIT and three categories of outcomes occurred 38 and 65 times, respectively.

Conclusions: A strong majority of the literature shows positive effects of HIT on the effectiveness of medical outcomes, which positively supports efforts that prepare for stage 3 of meaningful use. This aligns with previous reviews in other time frames.
\end{abstract}

(J Med Internet Res 2018;20(2):e41) doi: 10.2196/jmir.8793

\section{KEYWORDS}

health information technology; treatment outcome; electronic health record

\section{Introduction}

\section{Background}

Health information technology (HIT) is an umbrella term that covers a wide range of technologies that store, share, and analyze health information [1,2]. In this role, HIT can influence service quality and provider performance [3]. As stated by Wagner et al, the adoption of HIT for the purpose of improving medical outcomes was touted by the Institute of Medicine in numerous reports, including "The Computer-based Patient Records: An Essential Technology for Health Care" in 1991, "To Err is Human: Building a Safer Health Care System" in 2002, and "Patient Safety: Achieving a New Standard for Care" in 2004 [4]. Due to the costs associated with implementing HIT, initially, health care payers seemed to be the only stakeholders benefiting from it [4].

In the United States in 2009, the Health Information Technology for Economic and Clinical Health (HITECH) Act made incentive 
payments available to providers who adopted the meaningful use of a certified electronic health record (EHR), stimulating widespread adoption of HIT across various health care settings [4]. Since the implementation of the HITECH Act, adoption rates of the electronic medical record in the United States have shown greater than arithmetic growth [5], but have patients experienced a commensurate increase in quality and decrease in errors as a result of the presence of that technology? The same question applies internationally. In 2014, Denmark instituted a regional patient record system. In 2015, Switzerland adopted a nationwide EHR, and Germany issued chip-based medical cards to all statutory health insurance beneficiaries for health care claims. In 2018, Germany will penalize providers who do not participate fully in this program. Have outcomes followed these programs?

Over the last several years, many studies have examined a relationship between the use of HIT and resulting health outcomes, administrative efficiencies, and cost [1,2]. Most studies that we found after our initial interest demonstrated a positive relationship between the use of HIT and medical outcomes, and these studies spanned seven countries [6-12]. However, all but three lacked quality metrics [1,2,11]. Three previous studies reviewed relative literature published in various but distinct time frames from 1995 and 2010.

Buntin et al [1] evaluated the benefits of health information technology in 2011 using data available from 2007 to 2010. This was a continuation of effort from Chaudhry et al, who examined literature from 1995 to 2004 and Goldzweig et al, who examined literature from 2004 to 2007 [2,11]. These three reviews demonstrated higher standards of science in their analysis, and therefore, this review will examine the years from January 1, 2011 to July 31, 2017 to update the literature. A good question to ask, however, is how has this changed since the HITECH Act? What has been the result of medical outcomes, specifically, since the last high quality review was conducted [1]?

\section{Objective}

The purpose of this review was to evaluate the current literature demonstrating the impact of HIT adoption on medical outcomes. Using the same methods as Buntin et al, Chaudhry et al, and Goldzweig et al (2004, 2007, and 2011, respectively), we intended to carry this research forward into 2017 [1]. What is the effect of the adoption of health information technology on medical outcomes since 2011? The hypotheses are as follows:

Hypothesis 1: There is a positive association between the adoption of HIT and medical outcomes.

Hypothesis 0: There is no positive association between the adoption of HIT and medical outcomes.

\section{Methods}

\section{Eligibility Criteria}

The conduct of our review followed a measurement tool for the "Assessment of Multiple Systematic Reviews" (AMSTAR) [13]. The format of the review follows the Preferred Reporting Items for Systematic Reviews and Meta-Analyses (PRISMA) [14]. The search criteria matched that used by Chaudhry,
Goldzweig, and Buntin and colleagues. Papers were eligible for selection in this systematic review if they were published in the last 5 years in academic (peer-reviewed) journals, in English, whose full-text was available for analysis, and the papers addressed implementation of HIT and an association with an effect on medical outcomes expressed in terms of efficiency or effectiveness. We chose 5 years because that is the amount of time since the last review was published on this topic. We limited the search to peer-reviewed journals to ensure an acceptable element of quality to the papers we were analyzing. We made the decision not to include other systematic reviews in the analysis, but they were used in the Discussion section for comparison.

\section{Information Sources}

We queried two common research databases: Medical Literature Analysis and Retrieval System Online (MEDLINE) by PubMed and the Cumulative Index of Nursing and Allied Health Literature (CINAHL). We used key terms from the US National Library of medicine's medical subject headings separated by Boolean terms. Searches were conducted from July 1, 2017 to July 4, 2017.

\section{Search and Study Selection}

Searches in each database were nearly identical. Due to the differences in indexing methods between the databases, we had to slightly modify the search string and filters for each. We screened for date of publication to begin in 2007 until the end of June 2017. The filters in PubMed enabled us to screen out reviews. In CINAHL, we excluded MEDLINE because it was being collected separately from PubMed, and this eliminated most duplicates. Papers were placed into an Excel (Microsoft) spreadsheet shared among the reviewers. Remaining duplicates were removed. As a quality measure, only peer-reviewed journals were used in the selection process.

\section{Data Collection Process and Data Items}

Reviewers agreed ahead of time what to look for in each abstract. We focused on papers that described a technological intervention that follows the definition of previous reviews $[1,2,11]$ and that expressed medical outcomes in terms of either effectiveness or efficiency. After the initial search was completed, we removed duplicates and filtered. Each member of the review team read all of the remaining abstracts to ensure they were reviewed at least twice, as outlined by AMSTAR [15]. Independent notes were taken on a shared spreadsheet to inspire discussion. Two consensus meetings were held: one to identify the full-text papers for analysis and one to identify other observations for additional analysis. A statistic of agreement, kappa, was calculated.

\section{Summary Measures, Synthesis of Results, and Bias}

The summary measure used in this analysis was the medical outcome specified in terms of either efficiency or effectiveness. When clear statistics were listed, our team recorded them for our analysis. We also identified signs of bias that could have deleterious effect on the broad application of the results. Several papers only mentioned advantages of administrative efficiency, such as a shorter length of stay (LOS) and lower readmission rates. These were kept because, we reasoned, a shorter LOS 
could have been due to improved outcomes, and lower readmission rates could have been enabled with improved outcomes that would have otherwise caused the patient to return.

\section{Results}

\section{Eligibility Criteria, Information Sources, and Search and Study Selection}

Studies from PubMed and CINAHL that defined an HIT intervention and a corresponding effect on medical outcomes stated in terms of efficiency or effectiveness were eligible for selection. The search for this review was extensive, and the reviewers took care to be deliberate and thorough in their process.

\section{Data Collection Process and Data Items}

The initial search, as illustrated in Figure 1, resulted in 3636 results. After removing duplicates and filtering, the remaining 629 abstracts were read in their entirety by the two reviewers, as outlined by AMSTAR [15]. Independent notes were taken on a shared spreadsheet. After the first consensus meeting, 534 were eliminated because they did not report medical outcomes, 8 because they were editorials, 8 were protocols and reported

Figure 1. Literature search with inclusion and exclusion criteria.

$$
\text { CINAHL complete }
$$

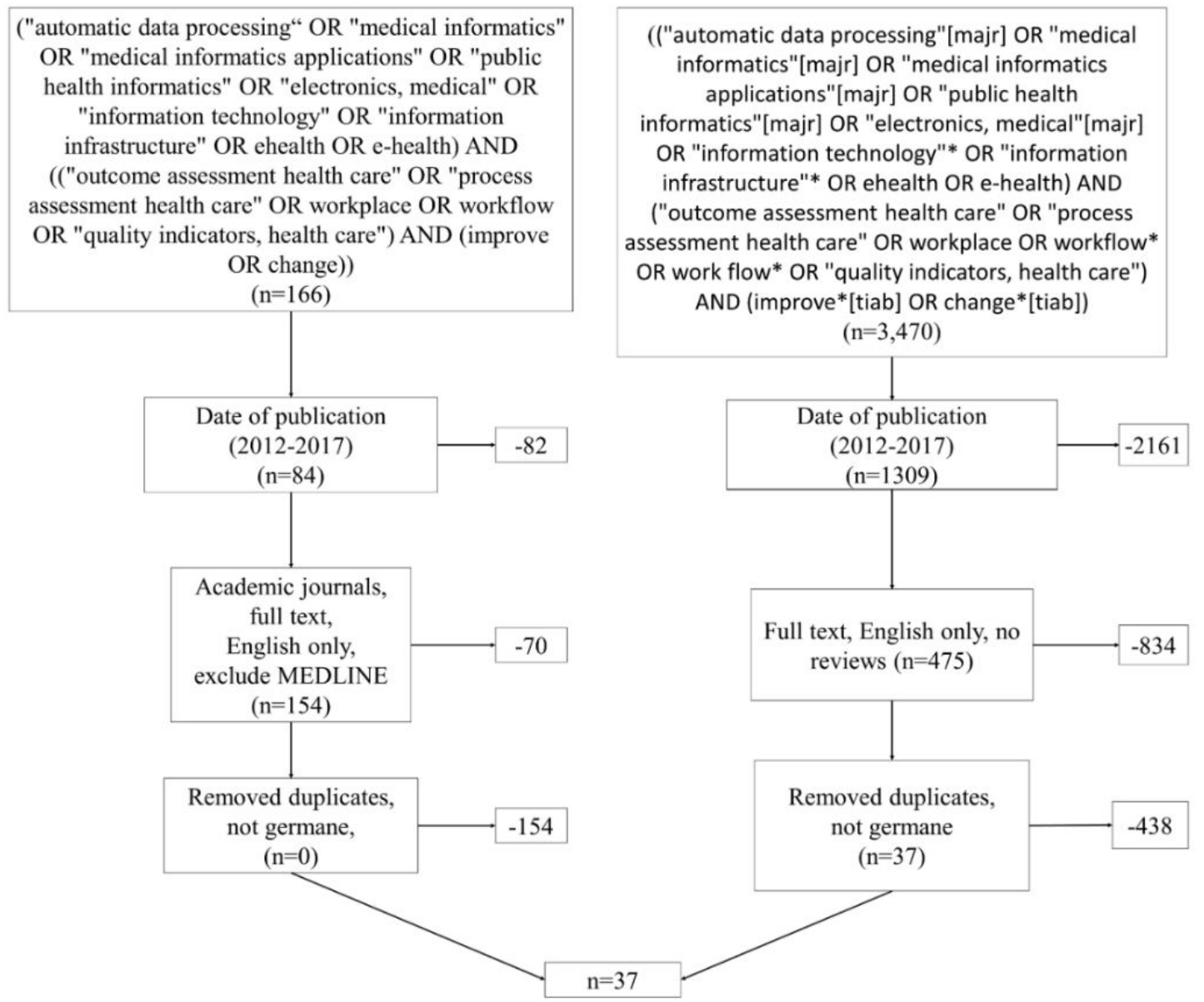

no results, 6 were models without results, and 6 were not germane to the objective. A statistic of agreement, kappa, was calculated to be .966 , which is indicative of a high level of agreement. Only 54 studies remained for full-text analysis, although some were kept under suspicion because the abstract was vague on whether or not outcomes were reported. A similar review approach was used for the analysis of the full-text papers. After the second consensus meeting, 15 more were removed for no medical outcomes and 2 removed for not being germane to the objective. The final set for analysis was 37 .

\section{Summary Measures, Synthesis of Results, and Bias}

Multimedia Appendix 1 summarizes the results of the analysis of the 37 studies chosen. It lists the descriptive title of the study, the HIT intervention, the measures of efficiency or effectiveness, and any bias observed that could limit the applicability of the results [15-51].

After consensus meeting number two, the categories of HIT recorded by each reviewer were combined. We counted the number of times that a category occurred in the literature and sorted by frequency of occurrence. This data was placed into an affinity matrix for further analysis (see Table 1).

PubMed

("automatic data processing"[majr] OR "medical formatics"[majr] OR "medical informatics ssessment health care" OR workplace OR workflow* AND (improve* $[$ tiab] OR change* $[$ tiab]) $(n=3,470)$ of publication $(\mathrm{n}=1309)$ 
Table 1. The specific categories of health information technology (HIT) and their frequency of occurrence.

\begin{tabular}{lll}
\hline Category of HIT $^{\mathrm{a}}$ & Paper in which category occurred & Frequency (n=38) \\
\hline Web-based & {$[19,31,34,41,44,45,47,51]$} & 8 \\
Telemedicine & {$[16-18,21,32,40,46]$} & 7 \\
Software & {$[25,27,28,30,36,50]$} & 6 \\
CDSS $^{\mathrm{b}}$ & {$[22,24,33,35,48]$} & 5 \\
mHealth $^{\mathrm{c}}$ & {$[20,42,45]$} & 3 \\
Telemonitoring & {$[29,37]$} & 2 \\
Electronic ordering & {$[26,38]$} & 2 \\
HIT & {$[49]$} & 1 \\
HIE & {$[43]$} & 1 \\
Robot assist & {$[15]$} & 1 \\
Videoconferencing & {$[23]$} & 1 \\
Remote screening & {$[39]$} & 1 \\
\hline
\end{tabular}

${ }^{\mathrm{a}}$ HIT: health information technology.

${ }^{\mathrm{b}}$ CDSS: clinical decision support systems.

${ }^{c}$ mHealth: mobile health.

${ }^{\mathrm{d}}$ HIE: health information exchange.

Table 2. The specific categories of outcomes and their frequency of occurrence.

\begin{tabular}{lll}
\hline Category of outcome & Paper in which category occurred ${ }^{\mathrm{a}}$ & Frequency $^{2}$ \\
\hline Physical & {$[15-17,23-26,28,30-35,37,39,41,42,44,45,48,49,51]$} & 39 \\
Psychological & {$[17-19,21,27,40,47]$} & 13 \\
Continuity of care & {$[20,22,23,25,27,29,36,39,40,43,46,50]$} & 13 \\
Total & Multiple occurrences in same paper & 65 \\
\hline
\end{tabular}

${ }^{\mathrm{a}}$ More than one occurrence was observed in the following papers in the categories of outcome; physical: 15-17, 23, 28, 37, 39, 41, 42; psychological: 18, 21, 27, 40; continuity of care: 23 .

Twelve different categories of HIT were identified in our analysis with a total of 38 occurrences. Web-based interventions were analyzed most frequently at 8 of 38 occurrences $(21 \%)$ $[19,31,34,41,44,45,47,51]$. Telemedicine and software programs were the next most frequently identified interventions, occurring 7 of 38 occurrences $(18 \%)$ [16-18,21,32,40,46] and 6 of 38 occurrences $(16 \%)$ [25,27,28,30,36,50], respectively. Clinical decision support systems were analyzed at a frequency of 5 of 38 occurrences $(13 \%)$ [22,24,33,35,48]. mHealth occurred 3 of 38 occurrences $(8 \%)[20,42,45]$. Telemedicine [29,37] and electronic ordering [26,38] HIT interventions occurred 2 of 38 occurrences (5\%). Health information exchange (HIE) [43], HIT [49], robot assistance [15], videoconferencing [23], and remote screening [39] were all identified once for the lowest frequency at $3 \%$ individually.

Table 2 tabulates the categories of outcomes and their frequency of occurrence.

The asterisks note that more than one occurrence was observed within the same paper. Evidence of efficiency or effectiveness that were grouped under physical outcomes included body mass index, blood pressure, hypertension, pain, infection, activities of daily living, mortality, vaccines nutrition, physical activity, cardiovascular disease, wound healing, diabetes distress, quality of life, A1C level, low-density lipoprotein, vaccination rate, sedation interruptions, spontaneous breathing trials, mechanical ventilations, asthma control, cholesterol, and cluster of differentiation 4 count. Occurrences grouped as psychological included depression, insomnia, self-efficacy, emotional stability, maintenance of motivation, upset, negative mood states, social outcomes, and eating disorder symptomatology. Continuity of care included medication administration, medication adherence, service utilization, readmission, length of stay, unmet needs, and reduced office visits. Although readmission, length of stay, and reduced utilization are qualities most often associated with administrative efficiencies, we chose to keep these in the review because these efficiencies could have been enabled because of improved medical outcomes. The most common outcome category was physical, which appeared 39 of 65 occurrences (60\%) [15-17,23-26,28,30-35,37,39,41,42,44,45,48,49,51]. The other two categories tied for second most often were as follows: psychological [17-19,21,27,40,47] and continuity of care $[20,22,23,25,27,29,36,39,40,43,46,50]$, which each occurrences 13 of 65 occurrences $(20 \%)$. Table 3 illustrates the categories 
of outcomes and the outcome results and their frequency of occurrence.

Table 3. Outcome results and their frequency of occurrence.

\begin{tabular}{lll}
\hline Result of outcome & Paper in which result occurred & Frequency $(\mathrm{n}=37)$ \\
\hline Improved & {$[18,20-29,31-35,37-46,48-51]$} & 30 \\
No statistical difference & {$[15-17,19,30,36,47]$} & 7 \\
\hline
\end{tabular}

Of the 37 papers included, $30(81 \%)$ reported an improvement in efficiency or effectiveness related to a medical outcome. No statistical difference in outcomes was reported in 7 of 37 occurrences (19\%) studies. These results strongly support our hypothesis; therefore, we accept our hypothesis and reject the null. There is a positive association between the adoption of HIT and medical outcomes.

We made 15 comments related to bias in the original research, the majority of which were related to the lack of heterogeneity in characteristics of participants. Characteristics that were noted include socioeconomic status, gender, age, ethnicity, and geographical area. Small sample size was noted as a potential concern in 4 studies, and participation refusal or dropout was noted in 2 studies. In one study, participants received payment for participation, and in another study, two of the authors had invented the technology being evaluated. Other sources of bias identified included outcomes reported based on a quality manager's response to survey, seasonal influences not controlled for, and technical challenges experienced that resulted in delays.

\section{Discussion}

\section{Summary of Evidence}

Health care providers will continue to be incentivized to adopt HIT as policy makers respond to quality, and safety concerns and reimbursement methods transition toward value-based purchasing [4]. Providers, consumers, and policy makers alike stand to benefit from the further proliferation of HIT. Our research aligns with previous work that identified improvements achieved as the result of the adoption of HIT [1,2,11]. The majority of research we identified, $81 \%$, in this review demonstrated improved medical outcomes in terms of efficiency or effectiveness as a result of HIT adoption. Although these findings are similar to the overall conclusions drawn by previous reviews, the adoption of HIT can have a positive impact on medical outcomes [1,2,11]. There are two key differences between our work and the three previous literature reviews.

First, Buntin et al reported that less than $10 \%$ of the studies included in their work demonstrated negative findings related to the adoption of HIT [1]. We identified a number of studies that demonstrated no statistical improvement, but we did not identify any negative impacts as a result of the adoption of HIT. Buntin et al noted that the majority of their negative findings were associated with provider satisfaction with HIT. We chose to only include papers that demonstrated effects of efficiency and effectiveness in terms of medical outcomes; this could account for the difference in our findings. Organizational factors related to the success of HIT implementation and improved medical outcomes is one area where further research is needed $[1,2,11]$.
Second, the literature review conducted by Chaudhry et al in 2004 noted that the improved outcomes demonstrated were reported by a limited set of large benchmark organizations and cautioned on the ability to generalize positive findings to other institutions [2]. Goldzweig et al and Buntin and colleagues identified the emergence of more widespread research outside larger and more established organizations [11,1]. One important finding noted by Goldzweig et al was an increased focus on patient-focused HIT. We believe this trend has continued through 2017. We identified a greater variety in the types of HIT being studied than previous literature reviews; Web-based interventions being the most frequently researched. This may be an indication of an increased rate of adoption of HIT and perhaps improved efficiency and effectiveness across a wider variety of health care settings.

One common theme in all four literature reviews is the limited amount of research associated with HIE specifically $[1,2,11]$. $\mathrm{HIE}$ is at the forefront of technological advancement in the health care industry [4]. Only one study in our review of recent literature included HIE. More research is needed to identify the outcomes associated with the adoption of HIT systems that are capable of information exchange.

\section{Limitations}

Our literature review did not identify any studies demonstrating a negative impact on medical outcomes as the result of HIT adoption. The absence of negative findings may be because of publication bias [1] and should be considered in the interpretation of these results. This is supported by the finding of $19 \%$ of studies that found no statistical difference in outcomes as a result of HIT. Another limitation of this work is the diversity in types of medical outcomes examined and the uniqueness of each sample studied. This impacts the ability to generalize findings across the industry. Furthermore, limiting our search to MEDLINE by PubMed and CINAHL may have impacted the scope of our results.

\section{Conclusions}

HIT has the potential to improve the quality and safety of health care services. Providers who leverage HIT to improve medical outcomes can position themselves for sustainability in the future. Further research is needed to continue to reveal and define the relationship between the adoption of HIT and medical outcomes. This will be especially true as the industry establishes new and innovative ways to integrate technological advances and works toward greater interoperability as the United States prepares for stage 3 of meaningful use, as all providers seek a link between the application of HIT in health care and its effect on outcomes, and as other nations such as Switzerland, Denmark, and Germany reconcile national medical programs such as a 
nationwide EHR, regional electronic patient record system, and national medical chip cards, respectively, against outcomes.

\section{Conflicts of Interest}

None declared.

\section{Multimedia Appendix 1}

Summary of analysis.

[PDF File (Adobe PDF File), 123KB-Multimedia Appendix 1]

\section{References}

1. Buntin MB, Burke MF, Hoaglin MC, Blumenthal D. The benefits of health information technology: a review of the recent literature shows predominantly positive results. Health Aff (Millwood) 2011 Mar;30(3):464-471 [FREE Full text] [doi: 10.1377/hlthaff.2011.0178] [Medline: 21383365]

2. Chaudhry B, Wang J, Wu S, Maglione M, Mojica W, Roth E, et al. Systematic review: impact of health information technology on quality, efficiency, and costs of medical care. Ann Intern Med 2006 May 16;144(10):742-752. [doi: 10.7326/0003-4819-144-10-200605160-00125]

3. Blumenthal D. Launching HITECH. N Engl J Med 2010 Feb 04;362(5):382-385. [doi: 10.1056/NEJMp0912825] [Medline: 20042745]

4. Wager KA, Lee FW, Glaser JP. Health Care Information Systems: A Practical Approach for Health Care Management. San Francisco, CA: Jossey-Bass; 2017.

5. Conn J. Modern Healthcare. 2016. Hospitals achieve 96\% EHR adoption rate; data exchange still needs work URL: http:/ /www.modernhealthcare.com/article/20160531/NEWS/160539990 [accessed 2017-08-09] [WebCite Cache ID 6sbNyijkx]

6. US Department of Health and Human Services. 2016. Adoption of electronic health record systems among U.S. non-federal acute care hospitals: 2008-2015 URL: https://dashboard.healthit.gov/evaluations/data-briefs/ non-federal-acute-care-hospital-ehr-adoption-2008-2015.php [accessed 2017-07-13] [WebCite Cache ID 6rvQ6UXk0]

7. Amarasingham R, Plantinga L, Diener-West M, Gaskin DJ, Powe NR. Clinical information technologies and inpatient outcomes: a multiple hospital study. Arch Intern Med 2009 Jan 26;169(2):108-114. [doi: 10.1001/archinternmed.2008.520] [Medline: 19171805$]$

8. Free C, Phillips G, Galli L, Watson L, Felix L, Edwards P, et al. The effectiveness of mobile-health technology-based health behaviour change or disease management interventions for health care consumers: a systematic review. PLoS Med 2013;10(1):e1001362 [FREE Full text] [doi: 10.1371/journal.pmed.1001362] [Medline: 23349621]

9. Ammenwerth E, Schnell-Inderst P, Machan C, Siebert U. The effect of electronic prescribing on medication errors and adverse drug events: a systematic review. J Am Med Inform Assoc 2008;15(5):585-600 [FREE Full text] [doi: 10.1197/jamia.M2667] [Medline: 18579832]

10. Ludwick DA, Doucette J. Adopting electronic medical records in primary care: lessons learned from health information systems implementation experience in seven countries. Int J Med Inform 2009 Jan;78(1):22-31. [doi: 10.1016/j.ijmedinf.2008.06.005] [Medline: 18644745]

11. Goldzweig CL, Towfigh A, Maglione M, Shekelle PG. Costs and benefits of health information technology: new trends from the literature. Health Aff (Millwood) 2009;28(2):w282-w293 [FREE Full text] [doi: 10.1377/hlthaff.28.2.w282] [Medline: 19174390$]$

12. Paasche-Orlow MK, Wolf MS. The causal pathways linking health literacy to health outcomes. Am J Health Behav 2007;31 Suppl 1:S19-S26. [doi: 10.5555/ajhb.2007.31.supp.S19] [Medline: 17931132]

13. Shea BJ, Grimshaw JM, Wells GA, Boers M, Andersson N, Hamel C, et al. Development of AMSTAR: a measurement tool to assess the methodological quality of systematic reviews. BMC Med Res Methodol 2007;7:10 [FREE Full text] [doi: 10.1186/1471-2288-7-10] [Medline: 17302989$]$

14. Moher D, Liberati A, Tetzlaff J, Altman DG, PRISMA Group. Reprint--preferred reporting items for systematic reviews and meta-analyses: the PRISMA statement. Phys Ther 2009 Sep;89(9):873-880. [Medline: 19723669]

15. Feinberg AE, Elnahas A, Bashir S, Cleghorn MC, Quereshy FA. Comparison of robotic and laparoscopic colorectal resections with respect to 30-day perioperative morbidity. Can J Surg 2016 Aug;59(4):262-267 [FREE Full text] [doi: 10.1503/cjs.016615] [Medline: 27240135]

16. Müller KI, Alstadhaug KB, Bekkelund SI. A randomized trial of telemedicine efficacy and safety for nonacute headaches. Neurology 2017 Jul 11;89(2):153-162 [FREE Full text] [doi: 10.1212/WNL.0000000000004085] [Medline: 28615434]

17. Schulz-Heik RJ, Meyer H, Mahoney L, Stanton MV, Cho RH, Moore-Downing DP, et al. Results from a clinical yoga program for veterans: yoga via telehealth provides comparable satisfaction and health improvements to in-person yoga. BMC Complement Altern Med 2017 Apr 04;17(1):198 [FREE Full text] [doi: 10.1186/s12906-017-1705-4] [Medline: 28376861] 
18. Hoaas H, Andreassen HK, Lien LA, Hjalmarsen A, Zanaboni P. Adherence and factors affecting satisfaction in long-term telerehabilitation for patients with chronic obstructive pulmonary disease: a mixed methods study. BMC Med Inform Decis Mak 2016 Feb 25;16:26 [FREE Full text] [doi: 10.1186/s12911-016-0264-9] [Medline: 26911326]

19. Ahmed AH, Roumani AM, Szucs K, Zhang L, King D. The effect of interactive web-based monitoring on breastfeeding exclusivity, intensity, and duration in healthy, term infants after hospital discharge. J Obstet Gynecol Neonatal Nurs 2016;45(2):143-154 [FREE Full text] [doi: 10.1016/j.jogn.2015.12.001] [Medline: 26779838]

20. Garofalo R, Kuhns LM, Hotton A, Johnson A, Muldoon A, Rice D. A randomized controlled trial of personalized text message reminders to promote medication adherence among HIV-positive adolescents and young adults. AIDS Behav 2016 May;20(5):1049-1059. [doi: 10.1007/s10461-015-1192-x] [Medline: 26362167]

21. Steffen AM, Gant JR. A telehealth behavioral coaching intervention for neurocognitive disorder family carers. Int J Geriatr Psychiatry 2016;31(2):195-203. [doi: 10.1002/gps.4312] [Medline: 26077904]

22. Utidjian LH, Hogan A, Michel J, Localio AR, Karavite D, Song L, et al. Clinical decision support and palivizumab: a means to protect from respiratory syncytial virus. Appl Clin Inform 2015;6(4):769-784 [FREE Full text] [doi: 10.4338/ACI-2015-08-RA-0096] [Medline: 26767069]

23. Summerfelt WT, Sulo S, Robinson A, Chess D, Catanzano K. Scalable hospital at home with virtual physician visits: pilot study. Am J Manag Care 2015 Oct;21(10):675-684 [FREE Full text] [Medline: 26633092]

24. Chow AL, Lye DC, Arah OA. Mortality benefits of antibiotic computerised decision support system: modifying effects of age. Sci Rep 2015 Nov 30;5:17346 [FREE Full text] [doi: 10.1038/srep17346] [Medline: 26617195]

25. Katzan IL, Fan Y, Speck M, Morton J, Fromwiller L, Urchek J, et al. Electronic Stroke CarePath: integrated approach to stroke care. Circ Cardiovasc Qual Outcomes 2015 Oct;8(6 Suppl 3):S179-S189 [FREE Full text] [doi: 10.1161/CIRCOUTCOMES.115.001808] [Medline: 26515207]

26. Urban MK, Chiu T, Wolfe S, Magid S. Electronic ordering system improves postoperative pain management after total knee or hip arthroplasty. Appl Clin Inform 2015;6(3):591-599 [FREE Full text] [doi: 10.4338/ACI-2014-12-RA-0114] [Medline: 26448800]

27. Priebe S, Kelley L, Omer S, Golden E, Walsh S, Khanom H, et al. The effectiveness of a patient-centred assessment with a solution-focused approach (DIALOG+) for patients with psychosis: a pragmatic cluster-randomised controlled trial in community care. Psychother Psychosom 2015;84(5):304-313 [FREE Full text] [doi: 10.1159/000430991] [Medline: 26278784]

28. Jack B, Bickmore T, Hempstead M, Yinusa-Nyahkoon L, Sadikova E, Mitchell S, et al. Reducing Preconception Risks Among African American Women with Conversational Agent Technology. J Am Board Fam Med 2015;28(4):441-451 [FREE Full text] [doi: 10.3122/jabfm.2015.04.140327] [Medline: 26152434]

29. Davis C, Bender M, Smith T, Broad J. Feasibility and acute care utilization outcomes of a post-acute transitional telemonitoring program for underserved chronic disease patients. Telemed J E Health 2015 Sep;21(9):705-713. [doi: 10.1089/tmj.2014.0181] [Medline: 25955129]

30. Semler MW, Weavind L, Hooper MH, Rice TW, Gowda SS, Nadas A, et al. An electronic tool for the evaluation and treatment of sepsis in the ICU: a randomized controlled trial. Crit Care Med 2015 Aug;43(8):1595-1602 [FREE Full text] [doi: 10.1097/CCM.0000000000001020] [Medline: 25867906]

31. Peiris D, Usherwood T, Panaretto K, Harris M, Hunt J, Redfern J, et al. Effect of a computer-guided, quality improvement program for cardiovascular disease risk management in primary health care: the treatment of cardiovascular risk using electronic decision support cluster-randomized trial. Circ Cardiovasc Qual Outcomes 2015 Jan;8(1):87-95 [FREE Full text] [doi: 10.1161/CIRCOUTCOMES.114.001235] [Medline: 25587090]

32. Zarchi K, Haugaard VB, Dufour DN, Jemec GB. Expert advice provided through telemedicine improves healing of chronic wounds: prospective cluster controlled study. J Invest Dermatol 2015 Mar;135(3):895-900 [FREE Full text] [doi: 10.1038/jid.2014.441] [Medline: 25290685]

33. Mishuris RG, Linder JA, Bates DW, Bitton A. Using electronic health record clinical decision support is associated with improved quality of care. Am J Manag Care 2014 Oct 01;20(10):e445-e452 [FREE Full text] [Medline: 25414982]

34. Heisler M, Choi H, Palmisano G, Mase R, Richardson C, Fagerlin A, et al. Comparison of community health worker-led diabetes medication decision-making support for low-income Latino and African American adults with diabetes using e-health tools versus print materials: a randomized, controlled trial. Ann Intern Med 2014 Nov 18;161(10 Suppl):S13-S22 [FREE Full text] [doi: 10.7326/M13-3012] [Medline: 25402398]

35. Eckman MH, Wise RE, Speer B, Sullivan M, Walker N, Lip GYH, et al. Integrating real-time clinical information to provide estimates of net clinical benefit of antithrombotic therapy for patients with atrial fibrillation. Circ Cardiovasc Qual Outcomes 2014 Sep;7(5):680-686 [FREE Full text] [doi: 10.1161/CIRCOUTCOMES.114.001163] [Medline: 25205788]

36. Dexheimer JW, Abramo TJ, Arnold DH, Johnson K, Shyr Y, Ye F, et al. Implementation and evaluation of an integrated computerized asthma management system in a pediatric emergency department: a randomized clinical trial. Int J Med Inform 2014 Nov;83(11):805-813 [FREE Full text] [doi: 10.1016/j.ijmedinf.2014.07.008] [Medline: 25174321]

37. Shane-McWhorter L, Lenert L, Petersen M, Woolsey S, McAdam-Marx C, Coursey JM, et al. The Utah Remote Monitoring Project: improving health care one patient at a time. Diabetes Technol Ther 2014 Oct;16(10):653-660 [FREE Full text] [doi: 10.1089/dia.2014.0045] [Medline: 24991923] 
38. Sonstein L, Clark C, Seidensticker S, Zeng L, Sharma G. Improving adherence for management of acute exacerbation of chronic obstructive pulmonary disease. Am J Med 2014 Nov;127(11):1097-1104 [FREE Full text] [doi: 10.1016/j.amjmed.2014.05.033] [Medline: 24927911]

39. Kahn JM, Gunn SR, Lorenz HL, Alvarez J, Angus DC. Impact of nurse-led remote screening and prompting for evidence-based practices in the ICU. Crit Care Med 2014 Apr;42(4):896-904 [FREE Full text] [doi:

10.1097/CCM.0000000000000052] [Medline: 24201176]

40. Pratt SI, Bartels SJ, Mueser KT, Naslund JA, Wolfe R, Pixley HS, et al. Feasibility and effectiveness of an automated telehealth intervention to improve illness self-management in people with serious psychiatric and medical disorders. Psychiatr Rehabil J 2013 Dec;36(4):297-305 [FREE Full text] [doi: 10.1037/prj0000022] [Medline: 24320837]

41. Nevedal DC, Wang C, Oberleitner L, Schwartz S, Williams AM. Effects of an individually tailored Web-based chronic pain management program on pain severity, psychological health, and functioning. J Med Internet Res 2013;15(9):e201 [FREE Full text] [doi: 10.2196/jmir.2296] [Medline: 24067267]

42. Licskai CJ, Sands TW, Ferrone M. Development and pilot testing of a mobile health solution for asthma self-management: asthma action plan smartphone application pilot study. Can Respir J 2013 Aug;20(4):301-306 [FREE Full text] [Medline: 23936890]

43. Ben-Assuli O, Shabtai I, Leshno M. The impact of EHR and HIE on reducing avoidable admissions: controlling main differential diagnoses. BMC Med Inform Decis Mak 2013;13:49 [FREE Full text] [doi: 10.1186/1472-6947-13-49] [Medline: 23594488]

44. Hooper DK, Kirby CL, Margolis PA, Goebel J. Reliable individualized monitoring improves cholesterol control in kidney transplant recipients. Pediatrics 2013 Apr;131(4):e1271-e1279 [FREE Full text] [doi: 10.1542/peds.2012-2374] [Medline: $\underline{23478865}$

45. Irvine AB, Gelatt VA, Seeley JR, Macfarlane P, Gau JM. Web-based intervention to promote physical activity by sedentary older adults: randomized controlled trial. J Med Internet Res 2013;15(2):e19 [FREE Full text] [doi: 10.2196/jmir.2158] [Medline: 23470322]

46. Fortney JC, Pyne JM, Mouden SB, Mittal D, Hudson TJ, Schroeder GW, et al. Practice-based versus telemedicine-based collaborative care for depression in rural federally qualified health centers: a pragmatic randomized comparative effectiveness trial. Am J Psychiatry 2013 Apr;170(4):414-425 [FREE Full text] [doi: 10.1176/appi.ajp.2012.12050696] [Medline: 23429924]

47. Wagner G, Penelo E, Wanner C, Gwinner P, Trofaier M, Imgart H, et al. Internet-delivered cognitive-behavioural therapy v. conventional guided self-help for bulimia nervosa: long-term evaluation of a randomised controlled trial. Br J Psychiatry 2013 Feb;202:135-141 [FREE Full text] [doi: 10.1192/bjp.bp.111.098582] [Medline: 23222037]

48. Robbins GK, Lester W, Johnson KL, Chang Y, Estey G, Surrao D, et al. Efficacy of a clinical decision-support system in an HIV practice: a randomized trial. Ann Intern Med 2012 Dec 04;157(11):757-766 [FREE Full text] [doi: 10.7326/0003-4819-157-11-201212040-00003] [Medline: 23208165]

49. Restuccia JD, Cohen AB, Horwitt JN, Shwartz M. Hospital implementation of health information technology and quality of care: are they related? BMC Med Inform Decis Mak 2012 Sep 27;12:109 [FREE Full text] [doi: 10.1186/1472-6947-12-109] [Medline: 23016699]

50. Erler A, Beyer M, Petersen JJ, Saal K, Rath T, Rochon J, et al. How to improve drug dosing for patients with renal impairment in primary care - a cluster-randomized controlled trial. BMC Fam Pract 2012 Sep 06;13:91 [FREE Full text] [doi: 10.1186/1471-2296-13-91] [Medline: 22953792]

51. Gustafson D, Wise M, Bhattacharya A, Pulvermacher A, Shanovich K, Phillips B, et al. The effects of combining Web-based eHealth with telephone nurse case management for pediatric asthma control: a randomized controlled trial. J Med Internet Res 2012;14(4):e101 [FREE Full text] [doi: 10.2196/jmir.1964] [Medline: 22835804]

\author{
Abbreviations \\ AMSTAR: Assessment for Multiple Systematic Reviews \\ CINAHL: Cumulative Index of Nursing and Allied Health Literature \\ EHR: electronic health record \\ HIE: health information exchange \\ HIT: health information technology \\ HITECH: Health Information Technology for Economic and Clinical Health \\ LOS: length of stay \\ MEDLINE: Medical Literature Analysis and Retrieval System Online \\ mHealth: mobile health \\ PRISMA: Primary Reporting Items for Systematic Reviews and Meta-Analysis
}


Edited by G Eysenbach; submitted 20.08.17; peer-reviewed by I Adeleke, C Fincham, S Garde, A Ekeland; comments to author 15.09.17; revised version received 17.09.17; accepted 04.10.17; published 05.02.18

Please cite as:

Kruse CS, Beane A

Health Information Technology Continues to Show Positive Effect on Medical Outcomes: Systematic Review

J Med Internet Res 2018;20(2):e41

URL: http://www.jmir.org/2018/2/e41/

doi: 10.2196/jmir.8793

PMID: 29402759

(C)Clemens Scott Kruse, Amanda Beane. Originally published in the Journal of Medical Internet Research (http://www.jmir.org), 05.02.2018. This is an open-access article distributed under the terms of the Creative Commons Attribution License (https://creativecommons.org/licenses/by/4.0/), which permits unrestricted use, distribution, and reproduction in any medium, provided the original work, first published in the Journal of Medical Internet Research, is properly cited. The complete bibliographic information, a link to the original publication on http://www.jmir.org/, as well as this copyright and license information must be included. 